\title{
AGRICULTURA FAMILIAR, COOPERATIVISMO E AGROECOLOGIA PROMOVENDO O DESENVOLVIMENTO TERRITORIAL SUSTENTÁVEL: O CASO DA COOPERATIVA DOS AGRICULTORES FAMILIARES DE POÇO FUNDO-MG E REGIÃO
}

\author{
Nathan Pereira DOURADO \\ Ana Rute do $V_{A L E}^{2}$
}

\begin{abstract}
Resumo
Diante do fracasso ambiental da agricultura orientada pelo paradigma da alta produtividade a qualquer custo é urgente a discussão a respeito de outro modelo: a agroecologia, com um enfoque científico que fornece bases conceituais e metodológicas para o redesenho de sistemas produtivos sustentáveis e o desenvolvimento rural sustentável. Esse processo vem ocorrendo com a cafeicultura no Sul de Minas, na qual a produção em bases agroecológicas tem transformado a realidade da agricultura familiar. Tomando como exemplo os produtores associados à COOPFAM (Cooperativa dos Agricultores Familiares de Poço Fundo e Região), esse trabalho analisa como a transição agroecológica contribuiu para a geração de um novo modo de organização e de produção agrícola, de modo a proporcionar inovação, maior dinamismo econômico e valorização da identidade camponesa, no município de Poço Fundo. E, nessa perspectiva, o cooperativismo, a organização social e assistência técnica especializada abrem novas possibilidades para viabilizar a consolidação de territórios agroecológicos de vida.
\end{abstract}

Palavras-chave: Desenvolvimento Rural. Agricultura familiar. Cafeicultura. Sustentabilidade.

\section{Abstract \\ Family farmers, cooperativism and agroecology promoting sustainable territorial development: the case of the Cooperative of Family Farmers of Poço Fundo-MG and region}

In the face of the environmental failure of the agriculture oriented by the "highproductivity at any cost" paradigm, it is imperative to discuss another model: agroecology, with a scientific approach that provides conceptual and methodological bases for the redesign of sustainable productive systems and sustainable rural development. This process is happening with the coffee sector in the South of Minas Gerais, where agroecology-based production has changed the reality of family farming. Taking the producers associated with COOPFAM (Cooperative of the Family Farmers of Poço Fundo and Region) as an example, this work analyzes how the agroecological transition contributed to the establishment of a new way of organization and agricultural production, in order to provide innovation, greater economic dynamism and valorization of smallscale farmer identity, in the municipality of Poço Fundo. And, from this perspective, the cooperativism, social organization and specialized technical assistance open up new possibilities to facilitate the consolidation of agroecological territories of life.

Key words: Rural Development. Coffee Growers. Sustainable agriculture.

\footnotetext{
1 Mestrando em Agroecossistemas - UFSC. E-mail: npdourado@hotmail.com

2 Docente do curso de Geografia - UNIFAL/MG. E-mail: ana.vale@unifal-mg.edu.br
} 


\section{INTRODUÇÃO}

Atualmente a discussão a respeito de um outro modelo de agricultura é urgente diante dos impactos ambientais gerados pelo modelo produtivista convencional e da crescente subordinação da agricultura familiar às cadeias agroindustriais. Torna-se necessário questionar as formas de apropriação produtiva (e destrutiva) do meio natural pelo homem. A Agroecologia emerge como uma ciência e práxis, que contrapõe a racionalidade agroindustrial hegemônica. Propõe um modelo de produção agrícola capaz de atender as diversas demandas da sociedade sem comprometer a integridade dos agroecossistemas e que ao mesmo tempo, seja economicamente viável e socialmente inclusiva.

Esse processo vem ocorrendo na cafeicultura no Sul de Minas desde a década de 1990, tendo se iniciado no município de Machado. A partir daí, vem transformando a vida dos trabalhadores(as) da agricultura familiar, que ao adotarem práticas sustentáveis na produção cafeeira, passam a ter um olhar completamente diferente sobre a natureza e um posicionamento crítico sobre a forma de produzir ditada pelos preceitos da Revolução Verde. Atualmente, o município de Poço Fundo destaca-se pelo grande número de agricultores familiares e pelo o pioneirismo de se trabalhar com a cafeicultura orgânica e o comércio justo. Por conta disso, esse trabalho parte da experiência dos produtores associados à COOPFAM (Cooperativa dos Agricultores Familiares de Poço Fundo e Região), para analisar como a transição agroecológica contribuiu para a geração de um novo modo de organização e de produção agrícola, de modo a proporcionar inovação, maior dinamismo econômico e valorização da identidade camponesa, no município.

Como procedimento metodológico, além do levantamento e revisão bibliográfica, foram coletados dados secundários e realizadas as observações em campo (observação assistemática), visando recolher e registrar os fatos da realidade para, confrontar o referencial teórico com a realidade empírica (BONÍ; QUARESMA, 2005). Também foram realizadas entrevista semiestruturada com o presidente da cooperativa e com cooperados de três propriedades, indicadas por ele, nas quais foi aplicado o instrumento Diagrama de Venn, retirado do método Diagnostico Rural Participativo DRP (VERDEJO, 2006) para compreender as interações entre os diferentes atores sociais que conformam o território estudado.

O trabalho se estrutura a partir da discussão sobre a agroecologia no contexto da agricultura familiar, para depois confrontar a produção cafeeira convencional com a agroecológica, no Sul de Minas, para então, adentrar ao caso da cafeicultura familiar no município de Poço Fundo e o papel da COOPFAM e, por fim, analisar a criação de redes e relações de reciprocidade nessa realidade.

\section{A CONFLUÊNCIA ENTRE AGRICULTURA FAMILIAR E AGROECOLOGIA NO SUL DE MINAS}

A insustentabilidade da agricultura denominada de moderna, movida pelo paradigma econômico da grande escala, a geração de divisas e a alta produtividade a qualquer custo, se traduz em degradação ambiental, baixo emprego de mão de obra, desigualdade social e redução das áreas destinadas à produção de alimentos (COSTABEBER; CAPORAL, 2003; WANDERLEY, 2011; ALTIERI, 2012). Junto a isso, ocorre a constante busca pela reprodução e independência dos agricultores(as) familiares, um processo denominado de recampesinação por alguns autores, como Ploeg 
(2006) e Wanderley (2011), que apontam para uma nova proposta de desenvolvimento rural que priorize os pilares da sustentabilidade e uma simbiose entre o ecossistema e o agricultor. Nesse sentido, numa perspectiva agroecológica, o campesinato é, mais que uma categoria histórica, é sujeito social que possui "uma forma de manejar os recursos naturais vinculado aos agroecossistemas locais" (GUZMÁN; MOLINA, 2013, p. 76).

A partir das contradições geradas pelo capitalismo, emergem em meio à globalização homogeneizadora, singularidades que foram ofuscadas. O lugar e a ecologia dos saberes dos excluídos assumem a centralidade. Estudos comprovam que as novas fontes de crescimento, inovação e dinamismo econômico das áreas rurais estão principalmente ligadas as peculiaridades dos patrimônios natural e cultural. E as tradições de uma economia baseada na agricultura familiar e camponesa, longe de ser um passivo a ser superado, são condições favoráveis para surgimento de iniciativas locais de desenvolvimento endógeno, baseadas em valores de cooperação, confiança e solidariedade (PUTMAN,1996; PECQUEUR, 2009). A partir desse entendimento, a agricultura familiar e camponesa de base agroecológica, pode ser considerada um modo de organização e produção adequado para o desenvolvimento territorial sustentável (CAPORAL; COSTABEBER, 2002; GUZMÁN; MOLINA, 2013), embora seja considerada como categoria social heterogênea, que possui diferentes dinâmicas internas de produção agrícola e reprodução social, (LAMARCHE, 1998; PLOEG, 2006). Daí a necessidade de uma análise específica em cada lugar, situação e tempo, para conhecer melhor o seu funcionamento e compreender suas particularidades nos diferentes territórios (FINATTO; SALAMONI, 2008).

A agroecologia entendida como um enfoque teórico e metodológico destinado a apoiar a transição dos atuais modelos de desenvolvimento e produção para estilos mais sustentáveis pode ser trabalhadas partir de duas escalas: em nível do desenvolvimento rural sendo o território a unidade de análise, ou a partir do redesenho dos processos produtivos, tomando o agroecossistema como unidade de análise e implementação (CAPORAL; COSTABEBER, 2002). Nesse estudo, adotaremos as duas escalas de análise, priorizando uma abordagem territorial, realizando uma pesquisa qualitativa, a partir de um o estudo de caso, como método de abordagem, de caráter exploratório (YIN, 2001).

A produção orgânica de café no Brasil teve início na década de 1990, na mesorregião Sul/sudoeste de Minas Gerais, tradicional na cafeicultura brasileira, caracterizada por relevo montanhoso, com altitudes de $800 \mathrm{~m}$ a $1400 \mathrm{~m}$ e clima tropicaltemperado, possibilitando a produção de cafés com alta qualidade (COELHO, 2005).

Com a extinção do Instituto Brasileiro de Café (IBC), o Estado acabou com a política de garantia de preço e compra das safras. Esse fato gerou uma competitividade entre os produtores, que passaram a se preocupar com qualidade dos grãos ofertados. Isso fez com que os produtores começassem a se organizar em torno de cooperativas e associações regionais, buscando uma melhoria na qualidade e diferenciação dos produtos. Dentre as iniciativas tomadas para diferenciar o café no mercado e agregar valor, destaca-se a produção de café orgânico. Na fase atual, com a crescente demanda por alimentos orgânicos e a busca por uma agricultura mais sustentável, o mercado de café orgânico está em plena ascensão no mundo, a exportação desse produto, de 2015 triplicou em relação a 2012. Esse mercado em crescimento é atendido em grande parte por agricultores familiares de base agroecológica (MOURA et al., 2015) e destinam-se principalmente ao mercado externo: Estados Unidos, Europa e Japão, com preços entre $20 \%$ e $50 \%$ superior ao do café convencional commodity (MOREIRA, 2003).

Diferentemente do café convencional, a produção agroecológica não sofre o impacto da bienualidade, entendida como o processo de alternância da quantidade 
produzida, devido a práticas de manejo convencional, prejudiciais que fazem com que a energia produzida no período seguinte seja direcionada mais à sua recomposição do que à produção de frutos (SOUZA, 2006). A explicação para que a quantidade produzida no sistema agroecológico seja estável e menos suscetível a doenças, está relacionada ao tipo de manejo da lavoura, além da redução dos custos de produção, pois diminui os inputs no sistema produtivo. A fertilização do solo, no sistema agroecológico, se dá pelo uso de biomassa e de outros materiais orgânicos gerados na unidade produtiva, ampliando a independência do agricultor na gestão dos recursos necessários à produção (MOREIRA, 2003).

\section{CAFEICULTURA FAMILIAR NO MUNICÍPIO DE POÇO FUNDO-MG: PAPEL DA COOPFAM E A CRIAÇÃO DE REDES E RELAÇÕES DE RECIPROCIDADE}

O município de Poço Fundo, localizado na mesorregião Sul/Sudoeste de Minas (Figura 1), possui uma área total de $475 \mathrm{~km}^{2}$, com uma população de 15.961 habitantes, sendo que cerca de $42 \%$ residem no meio rural (IBGE, 2010). De acordo com Censo Agropecuário, do total de 2.785 propriedades rurais existentes no município, $86 \%$ são unidades de produção familiar, sendo que $94 \%$ dos estabelecimentos rurais apresentam área menor que 50 hectares e dessas $49 \%$ possuem área total de até 10 hectares (IBGE, 2006).

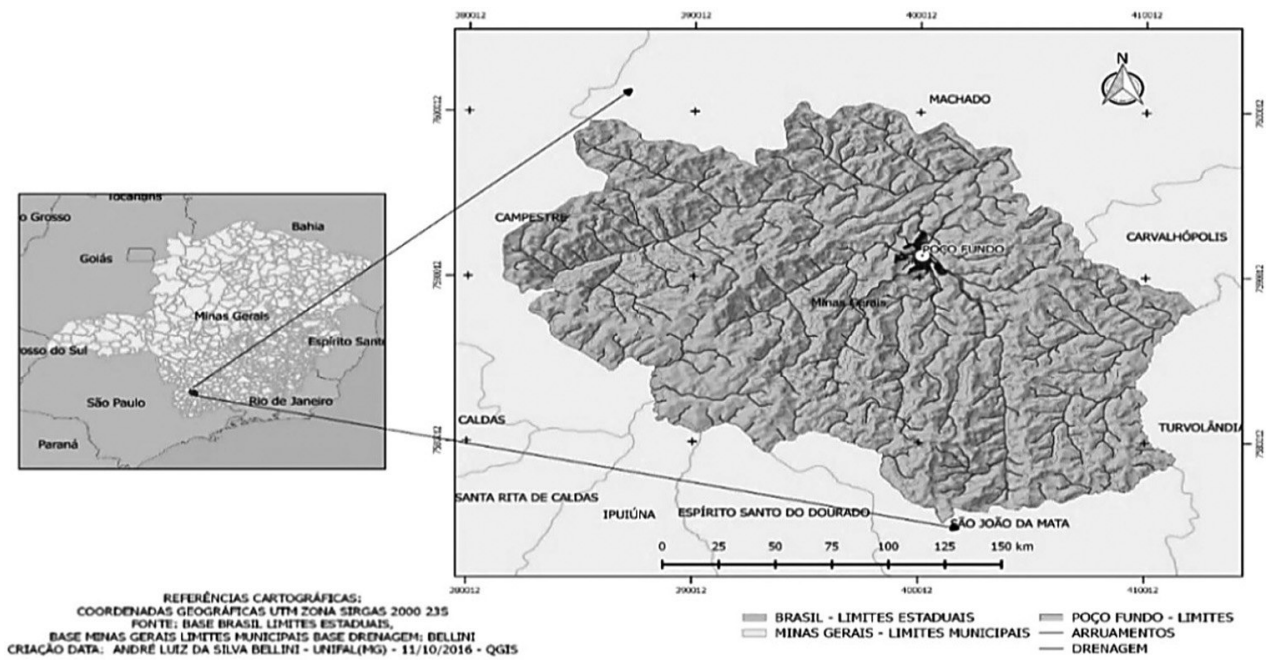

\section{Figura 1 - Mapa de localização do município de Poço Fundo no Estado de Minas Gerais}

A agropecuária é a atividade econômica mais importante em Poço Fundo e maior geradora de empregos, sendo que o cultivo de café representa $48 \%$ do total da área cultivada no município. Além do café, destaca-se a exploração de fumo, banana, milho, feijão e batata inglesa (EMATER, 2006). A maior parte da produção de café do município é comercializada pela COOPFAM, sendo que, das 439 de cafeicultores familiares associados, 421 são de Poço Fundo, com predomínio de pequenas propriedades 
(Tabela 1). Essa cooperativa teve início em 1991, com um grupo de pequenos agricultores familiares que fundaram a Associação dos Pequenos Produtores da Comarca de Poço Fundo. O objetivo do grupo era refletir sobre a realidade socioeconômica, política e ambiental vivida pelos pequenos produtores de Poço Fundo e promover a participação e mobilização em busca de condições mais justas e dignas de trabalho e comercialização. A partir disso, em 2003, com mais profissionalismo e organização a associação transformou-se em cooperativa e intensificou o corporativismo e a atividade comercial do grupo (PEREIRA, 2016).

\section{Tabela 1 - Tamanho da área das propriedades dos agricultores familiares cooperados da COOPFAM, do município de Poço Fundo-MG (2016)}

\begin{tabular}{lcc}
\hline $\begin{array}{c}\text { Área da propriedade } \\
\text { (ha) }\end{array}$ & $\begin{array}{c}\text { Número } \\
\text { (propriedades) }\end{array}$ & $\begin{array}{c}\text { Frequência } \\
\text { (\%) }\end{array}$ \\
\hline Menos de 05 & 182 & 43.2 \\
De 05 a 20 & 194 & 46.0 \\
De 21 a 50 & 33 & 7.8 \\
Mais de 50 & 12 & 2.8 \\
\hline Total & 421 & $100 \%$ \\
\hline
\end{tabular}

Fonte: COOPFAM (2016).

Apesar de ser o café o principal produto desse projeto, a produção orgânica também se estende aos hortifrutigranjeiros. O presidente argumenta que tal arranjo permite aos dirigentes da COOPFAM avançar na ideia segundo a qual a atenção ao abastecimento alimentar local constitui uma prioridade. Do total das 439 famílias cooperadas, 154 produzem de forma agroecológica ou já iniciaram a transição, sendo que 56 já possuem o selo orgânico. Ao se fazer a transição da produção convencional para a agroecológica, os custos de produção tornam-se menores por não necessitar da compra de agrotóxicos e produtos solúveis. A queda nos custos proporcionada por essa economia da agricultura orgânica é de $30 \%$ em média, podendo chegar a $70 \%$ em algumas produções (PEREIRA, 2016).

Além das adequações ambientais, faz parte das ações da cooperativa, seguir princípios internacionais que norteiam o comércio justo (fair trade), e que visam o desenvolvimento da comunidade, com destaque para os projetos de educação continuada de crianças, realização de cursos e treinamentos, programas de inclusão digital, atendimento a idosos e convênios de saúde, assessoria jurídica, construção de fossas sépticas rurais, dentre outros (PEREIRA, 2016). A certificação fair trade trata de aspectos éticos ligados à comercialização, tendo como característica a preocupação por parte dos consumidores, não só com a qualidade e o "valor biológico" dos produtos, mas também quanto às questões de cunho social e ecológico (CAVINO, 2012). No caso da COOPFAM, sua aquisição somente foi possível a partir da mudança na estrutura produtiva e organização democrática alcançada pela cooperativa. Além dessa certificação, o mercado internacional também exige a certificação que atestam a origem orgânica dos produtos, concedida pelo BCS Brasil, Ecocert, Instituto Biodinâmico (IBD-Botucatu/SP) ou pela Associação de Agricultura Orgânica (AAO/SP) (PEREIRA, 2016).

Com base nos dados fornecidos pela cooperativa, em 2015, foram produzidas 33.000 sacas de café convencional, 1.500 sacas de orgânico e 1.000 sacas de orgânico feminino. É importante ressaltar que esse último é um segmento da marca de café "Familiar da Terra", denominado "Familiar da Terra Orgânico Feminino", produzido por 
um grupo de mulheres, as quais têm direito a uma área na propriedade familiar, onde cultivam e recebem pela produção, separadamente. Essas mulheres são membros do MOBI - Mulheres Organizadas em Busca de Independência, grupo que surgiu em 2006, com o objetivo de lutar pela igualdade de direitos nas relações de gênero em seu meio social e familiar. Com o tempo, conquistaram o direito de decidir sobre as normas do seu principal produto, o café orgânico feminino e atualmente produzem flores e artesanatos para geração de renda. Quando a pesquisa foi encerrada, em 2016, a estimativa era fechar o ano com cerca de 40.000 sacas de convencional e 3.500 de orgânico e a expectativa é de que em 2018, a COOPFAM consiga produzir 8.000 sacas de orgânico. O investimento nesse modelo de produção torna-se atraente ao cafeicultor, uma vez que, em 2015, por exemplo, o valor pago pela saca de café convencional foi de aproximadamente $\mathrm{R} \$ 500,00$ e o orgânico de $\mathrm{R} \$ 980,00$, sendo que o café orgânico feminino recebe $10 \%$ a mais como forma de prêmio que é destinado para o grupo MOBI (PEREIRA, 2016).

Já existem muitos agricultores em processo de transição ou produzindo na forma SAT - sem uso de agrotóxicos -, que em breve poderão comercializar como orgânico. Segundo os entrevistados, os fatores que motivam os agricultores a trabaIhar com o sistema agroecológico, além do benefício econômico, é ver que as lavouras sem uso de agroquímicos estão ficando mais produtivas e com qualidade da produção superior. A COOPFAM realiza pesquisas de análise de solo, análise foliar, e de incidência de pragas, e já se pode comprovar essa melhoria na qualidade, isso tem encorajado os agricultores. Além desse aspecto, existe também a preocupação com a qualidade da saúde dos membros da família.

Dentre as dificuldades encontradas, tem destaque o aumento da demanda de mão de obra, por exemplo, quando substitui-se o uso de herbicida nos carreadores da lavoura, pelo controle manual do mato via capina. E em alguns casos observa-se uma dificuldade em manter a produtividade, sobretudo no início da transição, pois em alguns casos o solo encontra-se em desequilíbrio e precisa de tempo para recuperar a capacidade produtiva natural (PEREIRA, 2016). Todavia, por meio da criação de redes e relações de reciprocidade, esse agricultores estão conseguindo bons resultados.

As práticas associativas representam uma característica do capital social de uma sociedade, onde as relações horizontais como confiança, solidariedade e reciprocidade visam o benefício coletivo, e contribuem para o fortalecimento destas organizações. Conclui-se que a ação coletiva através da mobilização do capital social proporciona benefícios que indivíduos atuando de forma isolada provavelmente não conseguiriam, culminando na ideia de desenvolvimento territorial (PUTNAM, 1996).

Inicialmente cabe ressaltar que as três famílias de agricultores entrevistados tem sua origem no meio rural, do município de Poço Fundo e sempre trabalharam com agricultura, o que reforça o vínculo territorial e cultural com o meio em que vivem. Nos três casos, as unidades produtivas familiares, são formadas por pequenas áreas, que variam de 5 a 18 hectares, que receberam de herança, e foram aos poucos adquirindo e ampliando com o trabalho próprio. No entanto, possuem características diferentes, uma vez que no Sítio Cardoso a produção orgânica é diversificada, enquanto que no Sitio Terra Viva, a produção orgânica restringe-se apenas ao café, e no Sítio Macuco, a produção de café é convencional, todos com certificação fairtrade. É importante salientar que no caso do Sítio Macuco, embora ainda não produza em base agroecológica, caracteriza-se nas categorias de cooperação, trabalho familiar, solidariedade e comercio justo. Por meio do uso do instrumento diagrama de Venn, identificou-se os atores sociais, que foram classificados, a partir das entrevistas nas propriedades rurais, pelo grau de importância (tamanho do círculo) e também o grau de proximidade na relação (distância em relação à unidade produtiva), que serão analisados (Figura 2). 

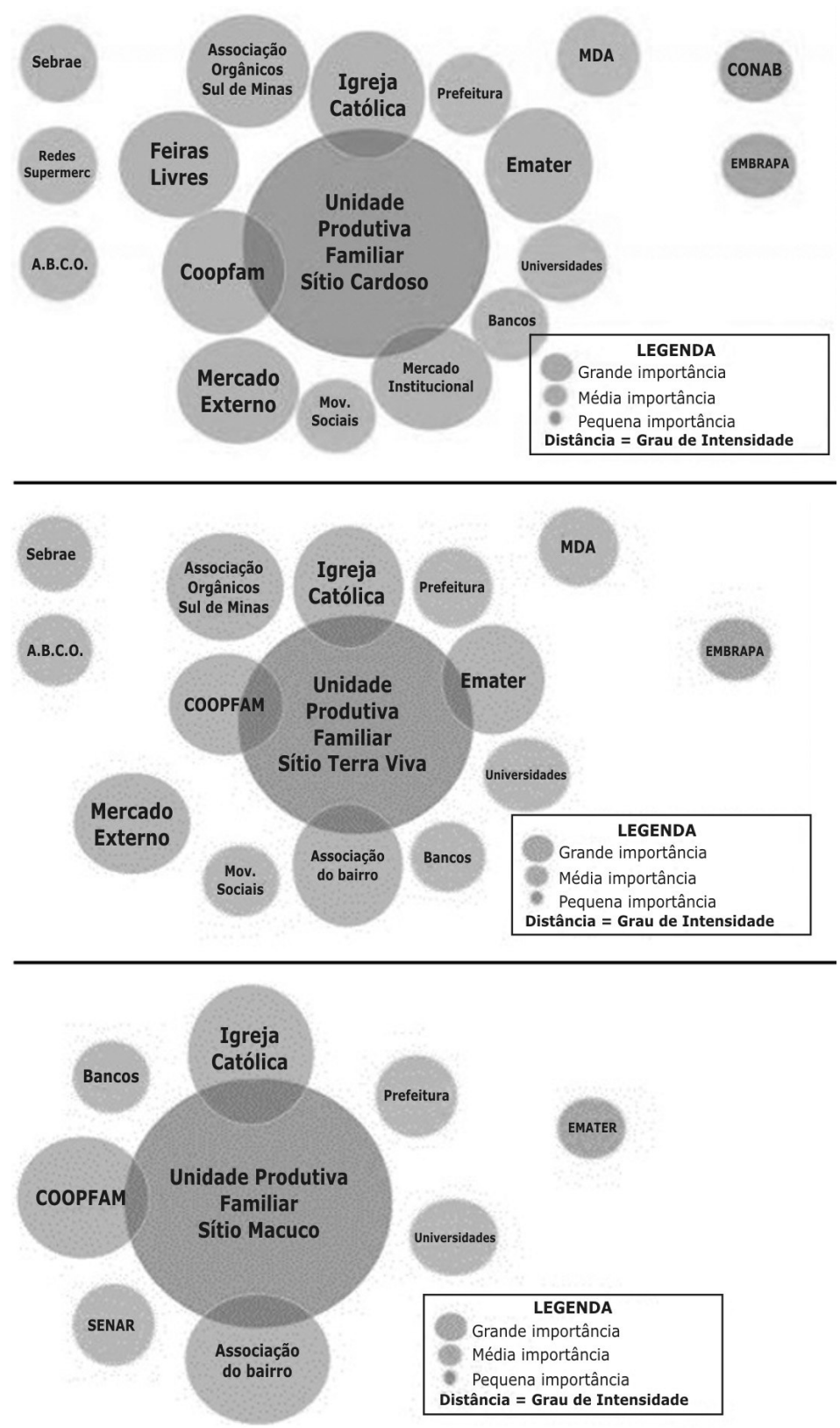

Figura 2 - Diagrama de Venn representando as relações entre atores sociais das seguintes propriedades rurais: Sítio Cardoso, Sítio Terra Viva e Sítio Macuco - município de Poço Fundo-MG

Fonte: Trabalho de campo, 2016. 
Nos três casos, a COOPFAM merece destaque, pois é de grande importância e proximidade em ambos os casos, representando um forte vínculo de confiança e governança democrática, sendo totalmente responsável pela comercialização do café produzido pelas famílias. A igreja católica apresenta grande importância e proximidade, pois está ligada à vida social das famílias, que frequentam semanalmente as missas e participam dos eventos promovidos na paróquia. A associação de bairro foi considerada de grande importância e grande proximidade também nas três propriedades, devido ao forte vínculo que a família mantém com essa instituição, que ajudaram a fundar e participam ativamente das reuniões, atividades e eventos, sendo importante para o convívio da comunidade e qualidade de vida dos moradores do bairro.

Outros dois atores sociais de grande importância, mas que foram representados com uma proximidade mediana, que indica uma menor intensidade de comunicação e troca, mas sem deixar de serem importantes: Associação Orgânicos Sul de Minas, por ser o órgão responsável pela certificação orgânica da propriedade. No entanto, atualmente, não tem tanta intensidade de contato, sendo que realiza visitas técnicas de auditoria com menor frequência. Conforme enfatizado pelas famílias entrevistadas, teve uma proximidade muito intensa no período de transição agroecológica e no processo de adequação para obtenção da certificação. E o mercado externo, que é o grande responsável pela compra do café, cerca de $95 \%$ da produção anual é vendida, na forma de grão cru, para a COOPFAM, que tem como destino final a exportação. Daí a grande importância para a família, embora não tenham relação direta, pois a venda é mediada pela cooperativa e por isso está representado no diagrama com uma distância mediana. No caso do Sítio Cardoso, o mercado institucional tem grande importância, pois sua produção diversificada atende ao PAA (Programa de Aquisição de Alimentos) e PNAE (Programa Nacional de Alimentação Escolar).

Em relação aos outros atores sociais representados, os bancos foram caracterizados como de média importância nos três casos, devido ao acesso à linha de crédito, como por exemplo, o PRONAF (Programa Nacional de Fortalecimento da Agricultura Familiar) com a linha para sistemas agroecológicos. Já a prefeitura de Poço Fundo, mantém uma relação de média importância e proximidade, devido aos serviços básicos prestados. As universidades e os movimentos sociais foram considerados de média importância e média proximidade em relação à unidade produtiva por manterem parcerias em projetos de pesquisa e extensão. Entre os atores que foram considerados de média importância, porém com maior distanciamento, destaca-se o extinto Ministério de Desenvolvimento Agrário, pelas políticas públicas de assistência aos agricultores familiares e aos eventos realizados, no qual segundo os agricultores são pouco frequentes. A Associação de Cafeicultura Orgânica, também pelos eventos realizados e o SEBRAE (Serviço Brasileiro de Apoio às Micro e Pequenas Empresas) pelos cursos prestados. A Embrapa (Empresa Brasileira de Pesquisa Agropecuária) foi considerada de pequena importância e grande distanciamento em ambos os casos, segundo as famílias, porque a instituição não atua na região prestando suporte aos cafeicultores familiares.

\section{CONSIDERAÇÕES FINAIS}

Apesar de apresentar vários casos de sucesso na região, sobretudo graças a COOPFAM, a cafeicultura familiar de base agroecológica encontra dificuldades em sua reprodução, tendo recebido pouca atenção e credibilidade das esferas governamen- 
tais, sendo visto simplesmente como um modismo. Isso aponta para a necessidade de um novo enfoque de um política voltada para o desenvolvimento rural a partir de uma perspectiva territorial em que as tradições camponesas passem a ser "uma fonte de inovação no plano de produção, da sociabilidade local e das instituições" (WANDERLEY, 2011 p. 125) Ainda assim, o desenvolvimento do setor orgânico é considerado uma oportunidade estratégica para o desenvolvimento econômico da agricultura familiar. E o cooperativismo, a organização social e assistência técnica especializada abrem novas possibilidades para viabilizar o desenvolvimento territorial sustentável e uma estratégia efetiva da agricultura familiar se inserir de maneira justa no mercado. Dessa forma, a mudança para um modo de produção agroecológico apresenta potencial para ampliar a autonomia, conservação e transmissão de um patrimônio sociocultural e a capacidade de reprodução social desse tipo de agricultor. Para tanto, é necessário uma nova proposta de extensão rural pública e gratuita e novas pesquisas e produção tecnológica voltadas para o enfoque agroecológico.

\section{REFERÊNCIAS}

ALTIERI, M. Agroecologia: bases científicas para uma agricultura sustentável. 3ed. rev. ampl. São Paulo, Rio de Janeiro: Expressão Popular, AS-PTA, 2012.

BONÍ, V.; QUARESMA, S. J. Aprendendo a entrevistar: como fazer entrevistas em Ciências Sociais. Em tese, Florianópolis, v. 2, n. 1, p.68-80, jan. 2005. Disponível em: https://periodicos.ufsc.br/index.php/emtese/issue/view/1354. Acesso em: 30 de ago. 2017.

CAVINO, V. C. O. A experiência de comercio justo de agricultores familiares da cooperativa Coopfam de Poço Fundo (MG): Identificando os obstáculos e as potencialidades da transição para a agricultura de base ecológica. 2012. $51 \mathrm{f}$. Dissertação (Mestrado em Agroecologia e Desenvolvimento Rural), Universidade Federal de São Carlos, Araras, 2012. Disponível em: https://repositorio.ufscar.br/handle/ufscar/149. Acesso em: 30 ago. 2017.

COELHO, F. M. G. O café num outro retrato do Brasil rural: o lugar da agricultura familiar. Informe Agropecuário, Belo Horizonte, v. 26, p. 9-16, 2005. Edição especial. Disponível em: http://www.sapc.embrapa.br/arquivos/consorcio/ informe_agropecuario/Cafeicultura_Familiar.pdf. Acesso em: 07 out. 2017.

COSTABEBER, J. A.; CAPORAL, F. R. Possibilidades e alternativas do desenvolvimento rural sustentável. In: VELA, Hugo (Org.). Agricultura Familiar e Desenvolvimento Rural Sustentável no Mercosul. Santa Maria: Editora da UFSM/Pallotti, 2003, p.157194.

EMATER. Plano Municipal de Desenvolvimento Rural Sustentável. Poço Fundo: Conselho Municipal de Desenvolvimento Rural Sustentável do Município de Poço Fundo/ MG, 2006.

FINATTO, R. A.; SALAMONI, G. Agricultura Familiar e Agroecologia: Perfil da produção de base agroecológica do município de Pelotas/RS. Sociedade \& Natureza, Uberlândia-MG, Dez./2008, p. 199-217. Disponível em: http://www.seer.ufu.br/ index.php/sociedadenatureza/article/view/9417. Acesso em: 07 out. 2017.

GUZMÁN, E. S.; MOLINA, M. G. Sobre a evolução do conceito de campesinato. São Paulo: Expressão Popular, 2013. 
IBGE. Censo Agropecuário 2006. Agricultura familiar. Primeiros resultados: Rio de Janeiro: IBGE, 2006, p. 199-217. https://ww2.ibge.gov.br/home/estatistica/ economia/agropecuaria/censoagro/agri_familiar_2006_2/default.shtm. Acesso em: 07 out. 2017.

Dados cidade 2010. Disponível em: http://www.ibge.gov.br. Acesso em: 07 out. 2017.

LAMARCHE, $H$. Por uma teoria da agricultura familiar. In: LAMARCHE, H. (Coord.). Agricultura familiar: comparação internacional - do mito à realidade. Campinas, Ed. Unicamp, 1998, p. 303-336.

MOURA, W. M. et al. Produção de café Arábica e Conilon em cultivo orgânico de base agroecológica. Informe Agropecuário, Belo Horizonte, v. 36, n. 287, p.40-52, nov. 2015.

MOREIRA, C. F. Caracterização de sistemas de café orgânico sombreado e a pleno sol no sul de Minas Gerais. Dissertação (Mestrado em Ecologia de Agroecossistemas). Escola Superior de Agricultura Luiz de Queiroz, Universidade de são Paulo, Piracicaba, 2003. Disponível em: http://www.teses.usp.br/teses/disponiveis/ 91/91131/tde-29072004-155514/pt-br.php Acesso em: 30 de agosto de 2017.

PEREIRA, Clemilson José. Entrevista concedida a DOURADO, Nathan Pereira. Poço Fundo, 09 jun. 2016.

PECQUEUR, B. A guinada territorial da economia global. Florianópolis: Eisforia, 2006. PLOEG, J. D. V. O modo de produção camponês revisitado. In: SCHNEIDER, S. (Org.) A Diversidade da Agricultura Familiar. Porto Alegre: EDUFRGS, 2006, p.13-54.

PUTNAM, R. D., Comunidade e democracia: a experiência da Itália moderna. Rio de Janeiro, FGV, 1996, p. 173-194.

SOUZA, M. C. M. Cafés sustentáveis e denominação de origem: a certificação de qualidade na diferenciação de cafés orgânicos, sombreados e solidários. Tese (Doutorado em Ciências Ambientais). Faculdade de Economia, Administração e Contabilidade, Universidade de São Paulo, 2006. Disponivel em: http:// www.teses.usp.br/teses/disponiveis/90/90131/tde-22112011-161753/pt-br.php Acessado em: 30 de agosto de 2017.

VERDEJO, M. E. Diagnóstico rural participativo: guia prático. Brasília, DF: MDA/ Secretaria da Agricultura Familiar, 2006. Disponível em: http://www.mda.gov.br/ sitemda/sites/sitemda/files/user_arquivos_64/Guia_DRP_Parte_1.pdf. Acesso em: 07 out. 2017.

WANDERLEY, M. N. B. Um saber necessário: os estudos rurais no Brasil. Campinas, SP: Editora da Unicamp, 2011.

YIN, Robert. K. Estudo de Caso: Planejamento e métodos. 4d. Porto Alegre: Bookmen, 2001. 